\title{
TRUST IN TECHNOLOGY
}

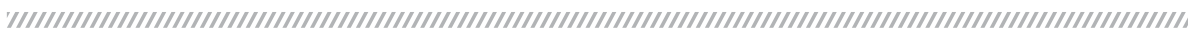

\section{Dear Reader,}

Hours before we were to put a wrap on this edition of Auto Tech Review, came a disturbing bit of news from Florida, US. Electric vehicle maker Tesla reported the first known death caused by a self-driving car, an incident that for sure would lead to widespread discussions in the industry and rekindle doubts among naysayers on why not to trust the booming autonomous vehicle industry.

The incident is actually a couple of months old, from May 2016. The Tesla Model S Joshua Brown was driving was put into the autopilot mode. As is reported, the vehicle's sensors failed to distinguish a large white 18-wheel truck and trailer crossing the highway against a bright spring sky. At full speed, Tesla reported, the car attempted to drive under the trailer, with the bottom of the trailer impacting the windshield of the Model S, and thus killing Brown.

Among a plethora of questions that will be asked, the most basic question is about how safe autonomous vehicles must be before they're ready to move people on highways and city streets. There is little doubt about the technology developing fast, and it getting better each passing day. But as Tesla said in its statement related to the incident, the technology "still requires the driver to remain alert”.

Apart from Tesla, Google, Delphi, Bosch, Nissan, Mercedes-Benz, Volkswagen, Ford, Toyota and even Uber expects that autonomous vehicles of SAE level 4 - a stage where the car would no longer need a driver, but may not be capable of driving everywhere - will be closer to being market-ready anytime over the next three to five years. Then, there are others like Continental that is betting on being able to offer fully autonomous vehicle technologies only by 2025 .

Advanced Driver Assistance Systems (ADAS) is considered to be a critical first step in the industry's transition to autonomous mobility. ADAS, in fact, is one of the key focus areas in our upcoming seminar on safety technologies on July 8, 2016; the other being automotive lighting. We have some fantastic presentations lined up on both these subjects. Stay tuned to our August 2016 edition for all relevant details. Until then, stay alert and drive safe!
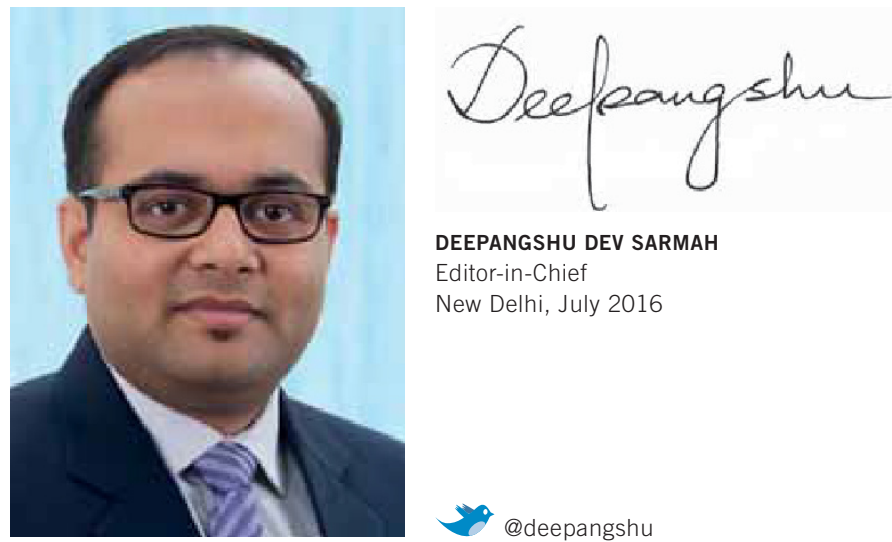

DEEPANGSHU DEV SARMAH

Editor-in-Chief

New Delhi, July 2016 